\title{
Análise de política como metodologia em estudo do transporte escolar rural ${ }^{1}$
}

\author{
Policy analysis as methodology in the study on the rural school transportation \\ Análisis de política como metodología en estudio del transporte escolar rural \\ CALINCA JORDÂNIA PERGHER \\ NALÚ FARENZENA
}

\begin{abstract}
Resumo: o texto apresenta o marco teórico-metodológico de análise de políticas públicas que fundamentou uma pesquisa sobre a política do transporte escolar rural no Rio Grande do Sul. São explicitadas diversas noções, conceitos e abordagens, mas a ênfase recai sobre a abordagem cognitiva, de linha francesa, e sobre a análise sequencial de políticas, suas características e o modo como foram combinadas na pesquisa. São narradas rotas percorridas na reconstrução analítica da política, nas fases de emergência do problema, colocação na agenda, formulação e adoção do programa e implementação.
\end{abstract}

Palavras-chave: análise de política pública; transporte escolar rural; políticas educacionais; transporte escolar no Rio Grande do Sul.

\begin{abstract}
The text presents the theoretical and methodological framework for public policies analysis that justified a research on the rural school transportation policy in Rio Grande do Sul. Several notions, concepts and approaches are explained, but the emphasis is on the cognitive approach, of French line, and in the sequential policy analysis, its characteristics and the way they were combined in the research. Routes covered in the analytical reconstruction of politics are narrated, in the emergency phases of the problem, putting on the agenda, formulation and affiliation to the program, and implementation.
\end{abstract}

Keywords: public policy analysis; rural school transportation; educational policies; school transportation in Rio Grande do Sul.

Resumen: El texto presenta el cuadro teórico y metodológico de análisis de políticas públicas fundamentó una investigación sobre la política de transporte escolar en el medio rural en Rio Grande do Sul, Brasil. Son explicitadas diversas nociones, conceptos y enfoques, pero el énfasis está en el enfoque cognitivo, de línea francesa, y en el análisis secuencial de políticas, sus características y la forma en que se combinaron en la investigación. Son narradas rutas recorridas en la reconstrucción analítica de la política, en las fases de emergencia del problema, colocación en la agenda, formulación y adopción del programa y puesta en marcha.

Palabras clave: análisis de política pública; transporte escolar rural; políticas educativas; transporte escolar en Rio Grande do Sul. 


\section{COMEÇO DO CAMINHO: DE POLÍTICA(S)}

No Brasil, falar em política é algo cotidiano e corriqueiro. É senso comum tratar a política como algo ruim, repulsivo e diretamente ligado ao conceito de partido político e, por consequência, a corrupção, escândalos, desvios de dinheiro e situações que pintam a política como grande vilã! Isso demonstra uma das dificuldades percebidas na compreensão, interpretação e utilização do próprio termo política.

Desse modo, iniciaremos a reflexão sobre política recuperando etimologicamente a palavra. Remotamente, no grego, polis (politikos) diz respeito a tudo que se refere à cidade: urbano, civil, público e, até mesmo, social ou sociável. No latim, politicus significa cidade, país ou nação (Estado). Cidade, do latim civitas, é comunidade política cujos membros se autogovernam. Para as línguas latinas, o termo política é polissêmico. Na língua inglesa, contudo, utilizam-se três palavras para denominar o que, para as línguas latinas, precisa ser feito apenas por uma, como explicam Muller e Surel (2002, p. 11): "Com efeito, este termo cobre, ao mesmo tempo, a esfera da política (polity), a atividade política (politics) e a ação pública (policies)".

Buscamos explicar sinteticamente esses três termos. A polity é a esfera da política que faz a diferenciação entre política e sociedade civil, é a parte institucional, a organização jurídico-política, o que pode ser condensado na expressão o político, como também na expressão as regras do jogo; no Brasil, por exemplo, são características da polity o federalismo, o presidencialismo, a organização do Estado em poderes, a organização partidária, as regras das relações intergovernamentais, a organização específica de cada setor de política, entre eles a organização político-administrativa da Educação. A atividade política, as relações políticas, os processos políticos, as relações intergovernamentais, a atuação dos partidos políticos, a competição política caracterizam a politics, e é essa a interpretação geralmente mais utilizada nas conversas informais quando é feita referência à política, podendo-se resumi-la como o jogo político. E, por fim, a policy refere-se à ação pública, às decisões/ações do Estado (policies, no plural), ou seja, o governo em ação através das políticas públicas.

Neste artigo, utilizaremos a amplitude do conceito e todas as suas abrangências para compreender a policy do transporte escolar; entretanto, essa ação não poderia ser observada sem a compreensão da politics e da polity. Procuramos levar em conta a competição política na oferta do transporte, as correlações de forças em diferentes momentos, a configuração das competências entre os entes federados, assim como as características institucionais que demarcam o campo de possibilidades da política que deve, pode ou é ofertada. 
Conforme define Parada (2006), a política e as políticas públicas são entidades diferentes, porém se influenciam de maneira recíproca; ambas têm relação com o poder social, mas a política é um conceito amplo, como já descrito, enquanto que as políticas públicas, segundo o autor, correspondem a soluções específicas de como tratar os assuntos públicos.

Tendo em conta estes entrelaçamentos, o objetivo do artigo é apresentar o marco teórico-metodológico que orientou uma pesquisa sobre a política pública de transporte escolar no Estado do Rio Grande do Sul. O estudo deteve-se, de modo mais aprofundado, na (re)construção do Programa Estadual de Apoio ao Transporte Escolar (Peate), programa esse inscrito em lei estadual no ano de 2008, prevendo regras da colaboração entre o governo do Estado e as prefeituras gaúchas na oferta do serviço de transporte escolar aos alunos da rede estadual de ensino. É importante esclarecer, contudo, que, dadas as próprias exigências de análise de políticas públicas, o período coberto pela pesquisa foi de 1999 a 2013, a fim de compreender as condições históricas da emergência do Peate, como também os anos iniciais de sua implementação.

Como próximo passo, conceituaremos neste artigo políticas públicas e políticas públicas educacionais; na sequência, apresentam-se elementos das abordagens cognitiva e sequencial de análise de políticas públicas, uma vez que foram combinadas no estudo. Em cada uma das seções, são explicitados conteúdos ou questões de pesquisa, a fim de ilustrar o modo como os aportes da análise de políticas públicas serviram à (re)construção analítica da política de transporte escolar rural no estado gaúcho.

\section{POLÍTICAS PÚBLICAS EDUCACIONAIS: ROTAS}

Os estudos sobre as políticas públicas têm sua origem nos Estados Unidos e rompem com a tradição europeia de análise do Estado e das instituições públicas, passando a analisar a produção dos governos. Conforme descreve Souza (2005),

$\mathrm{Na}$ Europa, a área de política pública vai surgir como um desdobramento dos trabalhos baseados em teorias explicativas sobre o Estado e sobre o papel de uma das mais importantes instituições do Estado, ou seja, o governo, produtor, por excelência, de políticas públicas. Nos EUA, ao contrário, a área surge no mundo acadêmico sem estabelecer relações com as bases teóricas sobre o papel do Estado, passando direto para a ênfase nos estudos sobre a ação dos governos (p. 2).

Essa mesma autora define o conceito do que seja análise de política pública como "O campo de conhecimento que busca, ao mesmo tempo, 
'colocar o governo em ação' e/ou analisar essa ação (variável independente) e, quando necessário, propor mudanças no rumo ou curso dessas ações (variável dependente)." (SOUZA, 2005, p. 5).

Muller e Surel (2002) trabalham a noção de políticas públicas agrupando três elementos: uma política pública constitui um quadro normativo de ação; ela combina elementos de força pública e elementos de competência (expertise); ela tende a constituir uma ordem local. Construímos o organograma a seguir para tornar mais visível essa definição dos autores e buscamos relacionar os conceitos a exemplos da política estudada, ou seja, o transporte escolar.

\section{Figura 1 - Noção de polícias públicas}

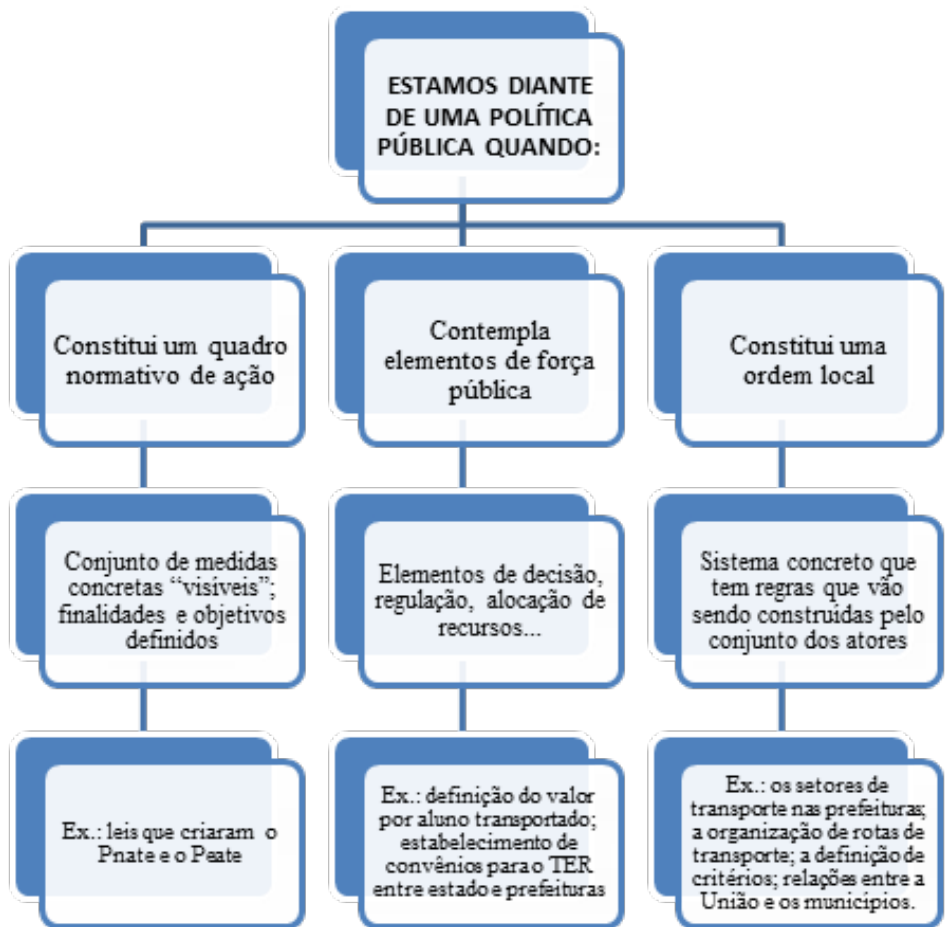

Fonte: Pergher (2014), baseadas em Muller e Surel (2002)

Esses três conjuntos de requisitos apresentados pelos autores auxiliam no desafio de compreendermos a complexidade do conceito.

De acordo com Parada (2006), uma política pública de excelência teria características que possibilitam uma melhor discussão política, sendo desenvolvida pelo setor público com a participação do setor privado e da comunidade. De fato, a tendência é partirmos do desejo de que as políticas públicas sejam de qualidade 
e, para tanto, perfeitas; entretanto, nem sempre esse ideal se concretiza e o que temos, na maioria das vezes, pelo menos no Brasil, são políticas públicas possíveis, contínuas e descontínuas, de governo e de Estado, horizontais e verticais.

$\mathrm{Na}$ literatura sobre as políticas públicas e sobre a ação pública, existem várias abordagens e diversos modelos: estatal, elitista, pluralista ou multicêntrica, neoinstitucional, cognitiva. Muller e Surel (2002) destacam que, até os anos 1970, duas abordagens partilharam o campo da análise do Estado: a abordagem estatal e a pluralista. Secchi (2010) as denomina abordagem estadista e abordagem multicêntrica e as apresenta como visões antagônicas. A abordagem estadista segue a lógica de que o Estado é o protagonista e indutor de políticas públicas, admitindo, apenas, que os atores não estatais tenham influência sobre o processo de elaboração. A abordagem multicêntrica compreende que as organizações não governamentais, privadas, organismos multilaterais, redes de políticas públicas (policy networks) e os atores estatais são todos possíveis compositores das políticas. Para a abordagem multicêntrica, uma política é pública quando o problema a ser enfrentado é público (SECCHI, 2010). Contudo, entendemos ser oportuno esclarecer que, na pesquisa realizada, utilizamos a noção de que a política pública não é sinônimo de política coletiva, mas, sim, implica fluxos de decisões e ações que contam com a intervenção e com o poder do Estado.

Em relação à abordagem neoinstitucional, Frey (2000) chama a atenção para o contexto dos sistemas políticos em transição e com instituições menos consolidadas - caso brasileiro - e que, para estes sistemas, as instituições, mais estáveis ou mais frágeis, podem ser fator determinante para explicar o sucesso ou o fracasso das políticas adotadas. O neoinstitucionalismo traz, do ponto de vista teórico, elementos relevantes que auxiliam na compreensão das políticas públicas; no Brasil, onde as relações e ações compartilhadas entre os entes federados ensejam negociações e disputas peculiares, essa abordagem auxilia, mas isso não significa que, sozinha, seja suficiente.

Outra abordagem, ainda pouco conhecida no Brasil, é a cognitiva. Segundo Muller e Surel (2002) essa abordagem se esforça por "apreender as políticas públicas como matrizes cognitivas e normativas, constituindo sistemas de interpretação do real, no interior dos quais os diferentes atores públicos e privados poderão inscrever sua ação" (p. 45). Ela confere peso significativo às ideias, às crenças, aos valores, enfim, às interpretações de mundo (do que é e do que deveria ser) por parte dos atores.

O motivo de esboçarmos aqui elementos do debate conceitual sobre políticas públicas não é o de enquadrarmos a pesquisa numa única teoria, abordagem ou modelo específico, mas por ser notável o entendimento de que a política do transporte escolar, em destaque a do Rio Grande do Sul (RS), não foi 
nem está sendo uma política discutida, formulada e implementada apenas pelo Estado - prefeitos, governador/a, Assembleia Legislativa, secretários municipais e estadual, Ministério Público, Poder Judiciário - e que outros atores -Federação das Associações de Municípios do Rio Grande do Sul (Famurs), União Nacional dos Dirigentes Municipais de Educação (Undime/RS), meios de comunicação social - foram e são protagonistas nessa construção. Ao mesmo tempo, os marcos institucionais existentes delineiam a política e interferem em sua constituição e evolução ao longo do tempo. Desse modo, concordamos com Souza (2005), quando argumenta que a política pública possa ser um campo holístico, no qual a visão do todo acaba por ser mais importante do que a soma das partes, "e que indivíduos, instituições, interações, ideologias e interesses contam, mesmo que existam diferenças sobre a importância relativa desses fatores” (p. 5).

As definições de políticas públicas são múltiplas e diversas; Secchi (2010) afirma que qualquer definição de política pública é arbitrária. De fato, não há consenso sobre o significado de política pública. Dentre autores e pesquisadores, as abordagens podem ser variadas. Não buscaremos fazer neste texto uma descrição de todas as abordagens e tipologias possíveis da área; apenas apresentamos as abordagens e os conceitos que, no momento, e tendo em consideração características institucionais do Brasil, acreditamos serem os mais adequados para a pesquisa enfocada.

Mediante os conceitos apresentados pelos autores estudados, ousamos resumir que, para nós, uma política pública é uma construção que pode ser tecida por vários atores; tem intenções e objetivos; carrega interpretações, sentidos e visões de mundo; nem sempre resolverá situações da forma desejada; é muitas vezes contraditória; geralmente vai construir uma nova representação dos problemas; pode-se aprender no processo de sua implementação e necessita tratar de um objeto público. Assim, para nós, educação é um dos objetos públicos.

Em se tratando de políticas públicas educacionais, e referindo-se ao Brasil, Farenzena (2011) considera que estas são decisões/ações governamentais que podem ser tanto do governo federal como de governos estaduais e municipais, e define as políticas públicas de educação:

Fluxos de decisões e ações em que se interpõe a autoridade do Estado, para o setor educação essas encerram: interações entre os agentes governamentais e a sociedade civil; a configuração institucional do Estado e da área da educação; o ordenamento jurídico, abrangendo direitos, garantias e condições de escolarização. (p. 103).

Os elementos acima referidos merecem ser levados em consideração quando se pretende analisar policies e demonstram que, ao se estudar uma política pública, se estudará a polity, a politics e os conteúdos próprios da policy. 
Cabe destacar que, historicamente, as políticas públicas brasileiras não se originaram de processos reflexivos e participativos envolvendo os atores de modo mais orgânico. Para Levinski (2011), "A construção e a vivência de políticas públicas educacionais adquirem sentido pedagógico na relação com os participantes, isto é, no processo participativo, representando uma opção teóricometodológica perante o mundo e a educação que queremos" (p. 4). A autora destaca o modo de implementação das políticas como algo determinante para a constituição de políticas com sentido.

Teoricamente, as políticas públicas educacionais, num Estado democrático de direito, terão por objetivo a efetivação da garantia do direito à educação, o qual poderá ser assegurado por políticas de acesso, de permanência ou de qualidade, ou de todos esses elementos congregados. A política do transporte escolar enfoca o acesso, pois não há dúvidas de que é dever do Estado garantir o acesso de crianças e adolescentes à escola; garantindo o acesso, garante-se o direito à educação. Também não restam dúvidas de que o modo ou a forma como será ofertado o acesso - que será por meio da política de transporte escolar - dará mais sentido público on qualidade a esse direito.

\section{PRIMEIRA VIA DE ANÁLISE: ABORDAGEM COGNITIVA}

Na policy analysis, não se dispõe de uma única teoria. Com teorias distintas, as combinações de abordagens têm sido muito utilizadas, até porque cada país tem suas peculiaridades. No Brasil, a análise de políticas públicas educacionais, embora iniciada recentemente, vem crescendo, tendo como objeto políticas federais, estaduais e municipais ou, bastante comum, políticas intergovernamentais, principalmente aquelas propostas pelo governo da União e implementadas com instâncias subnacionais. Nosso arranjo federativo é ímpar e traz alguns contornos que o fazem diferente de outros países até mesmo da América Latina, ainda mais se comparado a países europeus e norte-americanos. Desse modo, queremos tornar nítido que, ao utilizar abordagens já amplamente conhecidas e advindas de teóricos franceses e americanos, buscamos ter o cuidado, ao fazer análise da política do transporte escolar e ao utilizar essas teorias/abordagens, de situálas no contexto local (Brasil, Rio Grande do Sul, municípios gaúchos) e fazer a relação com o contexto mundial. Na continuação deste texto, apresentamos as abordagens escolhidas (cognitiva e sequencial), e procuramos indicar como foram utilizadas no estudo da política do transporte escolar rural gaúcho.

Para a abordagem cognitiva, as políticas públicas atuam sobre um setor da sociedade visando a adaptá-lo ou a transformá-lo. Essa ação sobre a sociedade é definida a partir de visões de mundo dos atores envolvidos na constituição 
das políticas. A definição dos problemas que merecem ser resolvidos, das soluções e das possíveis consequências passa pelas representações que os atores têm do problema, esse entendido aqui como situação social que merece intervenção do poder público. As políticas públicas, nessa abordagem, são muito mais do que processos de decisão, nos quais participam os atores; elas "são o lugar onde uma sociedade constrói sua relação com o mundo" (MULLER, 2010, p. 113).

Nesse sentido, elaborar uma política pública significa construir uma imagem da realidade na qual o Estado intervirá. Esse conjunto de imagens cognitivas, formado pela compreensão de mundo dos atores, será o referencial da política pública. Para cada situação, o referencial da política pública constitui um conjunto de normas prescritivas que vai construindo o sentido de uma política (Idem).

$\mathrm{Na}$ abordagem cognitiva, reconhecer o referencial em que está inserida a política pode passar por descrever o referencial global, o referencial setorial e a Relação Global-Setorial (RGS). O referencial global é uma representação ordenada por um conjunto de valores fundamentais que constituem as crenças básicas de uma sociedade. Ele geralmente ultrapassa a visão de Estado-nação. Para entender as sociedades atuais na sua complexidade, é preciso compreender os diversos elementos que compõem esse tecido social. Quando se faz a análise de uma política, é necessário - utilizando-se elementos da abordagem cognitiva - realizar essa leitura de contexto, ou seja, de referencial global, e descrever quais seriam os elementos que o compõem (Idem).

O referencial global traduz o contexto ideológico, os valores e as ideias relacionados ao papel do Estado na sociedade. O neoliberalismo, a governança social e o Estado de bem-estar social seriam exemplos de referenciais globais que têm se imposto mundialmente. Merrien (2008) assim fala sobre o neoliberalismo como referencial global:

Assim, já faz 30 anos, o neoliberalismo tornou-se a base ideológica de discursos e de proposições de reformas do Estado-providência e de políticas sociais no mundo. $\mathrm{O}$ antiestatismo e a importância conferida ao mercado constituem os temas essenciais que se traduzem, no domínio social, por recomendações de políticas de liberalização, de privatização, de focalização e de recuo do Estado-providência. $\mathrm{O}$ programa neoliberal é também um programa missionário (p. 321-322). ${ }^{2}$

2 Tradução feita por Nalú Farenzena (2011) do original em francês: "Ainsi, il y a maintenant trente ans, le néolibéralisme est devenu le socle idéologique des discours et des propositions de réforme de l’Étatprovidence et des politiques sociales dans le monde. L'anti-étatisme et l'importance accordé au marché constituent les thèmes essentiels qui se traduisent dans le domaine social par des recommandations de politiques de libéralisation, de privatisation, de ciblage et de recul de l’État-providence. Le programme néolibéral est aussi un programme missionnaire. 
O mesmo autor (MERRIEN, 2008), argumenta que a agenda neoliberal de reforma das políticas sociais se efetivou apenas num reduzido número de países e, além disso, sofreu mutações que alteraram sua natureza. Para ele, o referencial que tem hegemonia mais recentemente é o de governança social, em que a proteção social é estratégia de promoção de coesão social e de crescimento. O papel do Estado é reabilitado e os fracassos do mercado reconhecidos. Dessa mutação, contudo, não se deduz o retorno do Estado providência. A palavra de ordem é a governança: "A nova concepção afirma que a (boa) governança é aquela na qual o Estado se retrai, perde sua força, se torna modesto e trabalha em rede com interesses e grupos privados, na qualidade de parceiro apenas superior aos outros" (p. 317).

No Brasil, desde nosso ponto de vista, não podemos dizer que o Estado, através de suas políticas, é, na sua essência, neoliberal, ou totalmente enquadrado no paradigma da governança social. Mas também não podemos negar as evidências de muitas ações estatais neoliberais (como as privatizações) ou de governança social (como a organização gerencialista que viceja em muitos setores estatais ou as parcerias entre governos e setores não estatais na oferta de serviços públicos). Tampouco podemos negar a existência, ou persistência, de traços de um Estado de bem-estar social, pois temos regras e práticas - embora as regras superem as práticas - em áreas de políticas que buscam esse fim, como os sistemas únicos de Saúde e de Assistência Social e o sistema público de Educação Básica.

No caso brasileiro, o referencial global é híbrido, passa por uma construção de Estado nossa, em que o Estado nunca se assumiu neoliberal no sentido duro, nem se assumiu um Estado de bem-estar social puro. Sua principal característica tem sido o desenvolvimentismo - uma mescla de capitalismo, assistencialismo, gerencialismo, socialdemocracia. Oliveira (2003) fez, em julho de 2003, uma constatação, ou melhor, uma dura e sardônica crítica ao Brasil, comparando-o a um ornitorrinco: "O ornitorrinco é uma acumulação truncada e uma sociedade desigualitária sem remissão” (p. 150). Passados dez anos dessa crítica, o contexto político, social, econômico e educacional modificou-se, de forma híbrida, apresentando inúmeras incoerências. $O$ país não tem fugido, em sentindo amplo, do referencial global mundial hegemônico, mas tem dado a sua cara a ele. No referencial setorial da educação, temos políticas de gestão educacional do governo federal que visam a práticas de gestão gerencialista; ao mesmo tempo, temos políticas federais que objetivam a constituição da gestão democrática. Isso seria apenas um exemplo de hibridismo dentro do Ministério da Educação ${ }^{3}$. 
Muller (2010) define que o referencial articula quatro níveis de percepção do mundo que necessitam ser diferenciados: são os valores, as normas, os algoritmos e as imagens. Buscaremos explicar cada um desses quatros níveis, conforme o autor, e exemplificar através da política do transporte escolar que foi estudada.

- Por valores se compreendem as representações fundamentais sobre o que é bom e o que é mau. Exemplo: o debate sobre o direito à educação versus o direito ao acesso escolar, o fechamento de escolas rurais versus o transporte escolar.

- As normas definem as diferenças entre o que se tem e o que se quer. Exemplo: o transporte escolar deveria ser somente intracampo, as escolas rurais devem ser mantidas e a educação rural deve ser de qualidade.

- Os algoritmos são as relações causais que expressam a teoria da ação. Exemplo: se não tivessem nucleado e fechado as escolas rurais, hoje não teríamos tantos problemas e gastos com o transporte escolar. Se o transporte intracampo tivesse sido priorizado, hoje teríamos maior quantidade de escolas rurais em funcionamento.

- As imagens são os atalhos cognitivos que dão significado imediato ao que se faz. Nem sempre as políticas têm imagens reais, geralmente são ideias, conceitos, palavras, mas no caso em estudo há imagens possíveis de serem materializadas, há uma figura pública e um tipo de veículo que foram lembrados por diversos entrevistados, e entendemos que esta seria uma imagem concreta da política. Para a política investigada, as imagens que são atalhos imediatos são: a da Kombi escolar com o desenho do lápis sendo apontado e a figura da pessoa da ex-secretária estadual de educação no ano de 1993, professora Neuza Canabarro.

Os referenciais setoriais representam os setores. Na política em estudo, a educação é que seria esse setor ${ }^{4}$, e cabe situar, descortinar qual é o referencial da educação, retirando elementos de contexto, que estarão ligados ao referencial global; essa relação, por sua vez, é dialética. Haverá momentos em que ocorrerão defasagens com o quadro de interpretação global, e o real será privado de sentido (MULLER, 2000).

Em síntese, os elementos de contexto na análise cognitiva são imprescindíveis para a compreensão dos referenciais. No estudo realizado, utilizamos elementos da abordagem cognitiva com o propósito de construir pontes entre o global e o local e de auxiliar na compreensão dessas construções de sentido, permeadas por subjetividades, como é o caso do modo como se compreende o poder. A propósito disso, Muller (2000) elucida: 
A análise cognitiva das políticas não pode, pois, ser separada da dimensão do poder. Isso significa que o processo de emergência e, depois, do fortalecimento de um referencial (isto é, de uma nova visão de um problema, de um setor ou da sociedade) está muito longe de tomar a forma de um "debate de ideias" consensual. Ao contrário, este processo se caracteriza muitas vezes por formas de violência econômica, social e mesmo física. Isso se prende ao fato de que o processo de formulação e de imposição dos quadros de interpretação do mundo (os referenciais) não se faz nunca sem tocar mais ou menos brutalmente nas identidades coletivas dos atores implicados (p. 196).

Tal afirmação trouxe uma questão para a pesquisa realizada: em que medida as identidades coletivas da população do campo foram afetadas com a política de nucleação e transporte escolar?

\section{SEGUNDA VIA DE ANÁLISE: ABORDAGEM SEQUENCIAL}

Quanto à abordagem sequencial, a ideia principal é que cada política passa por diferentes etapas, sintetizadas em formulação, implementação e avaliação. Para compreender essas etapas, existem diversos conceitos e modelos teóricos. O estudo da elaboração de políticas, de sua colocação na agenda, de análise de sua implementação e de avaliação tem crescido e ganhado importância na comunidade acadêmica. Uma abordagem conhecida e utilizada durante muito tempo nos estudos de políticas é a sequencial, a qual, segundo Muller e Surel (2002), permanece como "um conjunto pertinente de meios heurísticos" (p. 26). Essa abordagem é didática e separa as políticas "em uma série de sequências de ação, que correspondem ao mesmo tempo a uma descrição da realidade e à criação de um tipo ideal de ação pública" (Ibidem). Seguindo a exposição dos autores, são seis as etapas: 1) a colocação na agenda (agenda setting); 2) a produção das soluções ou alternativas; 3) a decisão no sentido próprio (policy formulation); 4) a implementação (implementation); 5) a avaliação (policy evaluation); 6) a conclusão do programa (program termination).

A quantidade de fases ou etapas e as denominações que a elas atribuídas podem variar conforme as interpretações dos autores. Secchi (2010) apresenta sete fases do ciclo de políticas (policy cycle), como também é denominada a abordagem sequencial: 1) identificação do problema; 2) formação da agenda; 3 ) formulação de alternativas; 4) tomada de decisão; 5) implementação; 6) avaliação; e 7) extinção. Comparando as fases apresentadas por Muller e Surel (2002) com a descrição de Secchi (2010), é possível verificar que o segundo autor apresenta uma fase a mais - a identificação do problema - antes da colocação na agenda. Quanto às demais, mudam apenas denominações. Poderíamos seguir essa listagem apontando as diversas releituras e subdivisões feitas da ideia original de Charles 
Jones. Entretanto, entendemos ser mais significativo reconhecer os limites e as potencialidades desse modelo teórico, tendo em vista que não pretendemos seguí-lo de forma global e linear, até porque atualmente há uma multiplicidade de abordagens que fogem a esse ponto de vista faseológico e que colaboram na compreensão das características de uma ou outra fase de forma interdependente. Com certeza, mais rico será o processo de investigação e análise se as escolhas forem enlaçadas com o objeto de pesquisa sem a preocupação de seguir um único modelo e, sim, buscando aproveitar a diversidade metodológica existente e dela retirar os subsídios que irão auxiliar na análise desse ou daquele objeto. Foi essa a opção no estudo da política de transporte escolar rural no Rio Grande do Sul.

Com isso, não estamos dizendo que não utilizamos algumas etapas, mas o fizemos compreendendo que as políticas nem sempre são pensadas, formuladas e implementadas seguindo necessariamente uma trajetória coerente e coesa das fases expostas, e que essas fases possivelmente se interliguem e se relacionem num processo muitas vezes disforme. Cabe destacar que, dentre os cuidados necessários, ao utilizarmos um modelo de abordagem sequencial para análise de políticas, destaca-se a importância de se perceber, e se contornar, sua linearidade ao tratar da ação pública. Sendo isso um inconveniente, essa característica pode transportar um analista não muito vigilante a subestimar o caráter muitas vezes caótico das políticas públicas. Isso significa que muitas vezes a definição do problema pode ocorrer após a decisão, demonstrando a não sequência ou até mesmo a inexistência de algumas etapas (MULLER; SUREL, 2002).

Tendo o cuidado e a clareza de que o processo de política pública, como afirma Secchi (2010), "é incerto, e as fronteiras entre as fases não são nítidas" (p. 34), a abordagem sequencial, como já afirmado, é didática e heurística. A seguir, na Figura 2, apresentamos o desenho das fases consideradas as mais pertinentes para a realização da pesquisa sobre a política do transporte escolar no RS. 
Figura 2 - Fases analisadas na política do transporte escolar no RS

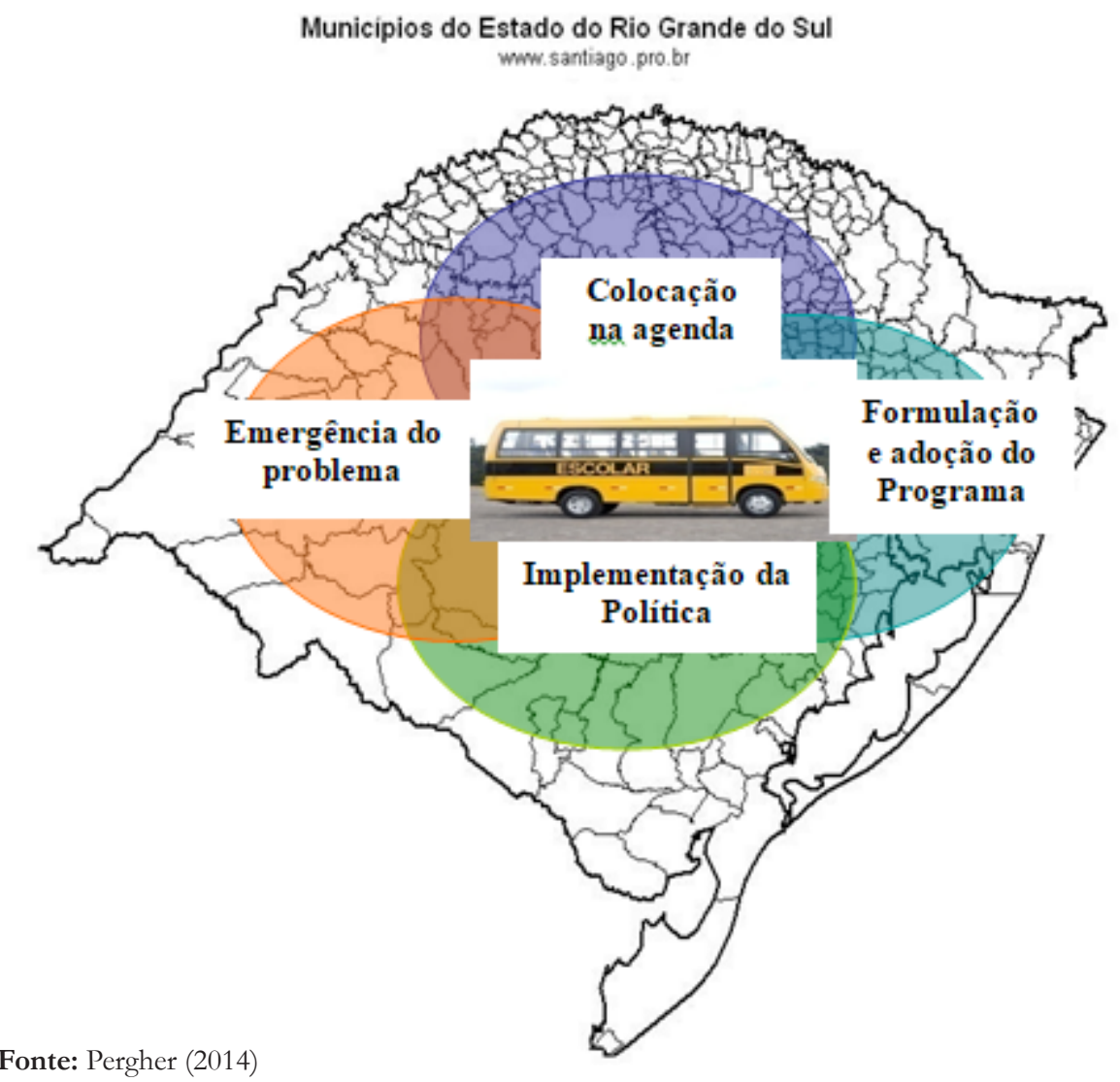

Procuramos compendiar o que corresponde a cada etapa/fase, utilizando a compreensão de alguns autores, como Muller e Surel (2002), Souza (2005), Kingdon (2006), Capella (2005) e Secchi (2010). As etapas escolhidas e apresentadas na Figura são complementadas pela explicitação de algumas questões de pesquisa.

a) Identificação ou emergência do problema: quando se toma consciência de que um problema é público, ou seja, de que uma situação que ocorre na sociedade merece ser modificada mediante a intervenção do poder público. Conforme Secchi (2010), "Um problema público é a diferença entre o que é e aquilo que se gostaria que fosse a realidade pública”. Questões norteadoras da pesquisa: como e quando se deu a tomada de consciência no RS de que o transporte escolar era um problema? Quais são os conteúdos que circularam na sociedade gaúcha no que 
concerne ao problema e à solução da responsabilidade pelo transporte escolar?

b) Colocação na agenda: "Como chega a hora de uma ideia?” (KINGDON, 2006, p. 219). Como já mencionado, vários têm sido os modelos teóricos que vêm auxiliando na compreensão do processo de formulação de políticas públicas. Um dos modelos utilizados é o de Multiple Streams, de Kingdon, o qual procura responder à seguinte questão: "por que alguns problemas se tornam importantes para um governo? Como uma ideia se insere no conjunto de preocupações dos formuladores de políticas, transformando-se em uma política pública?" (CAPELLA, 2005, p. 1). Questões norteadoras da pesquisa: como o Programa Estadual de Apoio ao Transporte Escolar (Peate) foi recentemente (2008) implementado no Rio Grande do Sul, a questão de pesquisa específica desta etapa diz respeito ao resgate da trajetória de quando e por quê foi colocada a temática do financiamento estadual do transporte escolar na agenda, quais atores foram fundamentais nesse debate e nessa disputa. Como foram sendo costurados os acordos de convênios entre estado e municípios? Como foi o processo de discussão e constituição do Peate? Quais atores estiveram envolvidos na constituição e na colocação dessa política na agenda? Quais foram as propostas dos atores? Quais foram os referenciais dessas propostas?

c) Formulação e adoção do programa/política: aqui é o momento de produzir alternativas. Após identificar o problema e colocá-lo na agenda, na pauta, é hora de juntar esforços e combinações para buscar soluções. A formulação de soluções passa pelo entendimento ou significação do problema e pelo planejamento de objetivos e estratégias. É o momento do processo decisório, o qual é complexo e pode revelar relações conflituosas entre os atores. Nessa etapa, compreendemos que produção e decisão podem ser tratadas juntas e não precisam ser separadas em etapas distintas. Assim, concordamos com Muller e Surel (2002), quando explicam que "na realidade é muito difícil isolá-la [a fase de decisão] com precisão, na medida em que ela ultrapassa o estrito quadro institucional" (p. 26). Outra reflexão que faz jus à evidência dessa etapa é de que a formulação pode ser uma etapa permanente, ou seja, enquanto se implementa pode se reformular, bem como, após, avaliar. Questões norteadoras da pesquisa: quais foram as soluções propostas pelos municípios através de suas representações e quais foram aceitas pelo governo estadual e pela Assembleia Legislativa na produção de soluções/ alternativas para a formulação da política/programa de transporte escolar no RS? Que processos decisórios foram constituídos pelos diversos atores na busca de 'soluções' aos problemas/impasses?

d) Implementação da política/programa: essa é a fase de colocar em prática as decisões formuladas nas etapas anteriores; é a política em ação. Segundo Souza (2005), essa etapa não tem sido muito pesquisada pelos analistas em políticas 
públicas. A autora destaca a importância de analisar a implementação de políticas por ser um estágio intermediário entre a formulação e a avaliação. Em relação aos problemas de implementação de políticas, Souza enfatiza que estes “estão situados no seu desenho, nas questões organizacionais e gerenciais ou em apenas um dos principais atores que implementam a política pública, ou seja, a burocracia ou as organizações que recebem delegação do governo para implementá-la" (Souza, 2005, p. 19). Existe, segundo a autora,

Uma miríade de variáveis que também impactam a política pública e somente estudos de caso específicos podem identificá-la. A correta identificação dessas variáveis e da sua influência na implementação das políticas públicas é o ponto-chave para corrigir seus possíveis problemas. (Ibidem).

Questões norteadoras da pesquisa: que variáveis impactaram a implementação da política do transporte escolar no RS? As decisões do poder executivo estadual e da Assembleia Legislativa foram implementadas? De que modo? Como o Peate/ RS tem sido colocado em prática? A política tem sofrido reformulações em sua implementação? Quais? Quais foram os motivos das reformulações?

Por fim, cabe pontuar que as etapas de avaliação da política e conclusão on extinção não foram abordadas na pesquisa, tendo em vista que a política de transporte no RS, formulada através do Programa Estadual de Apoio ao Transporte Escolar (Peate), é um programa recente. Mesmo assim, destacamos abreviadamente as duas etapas. A avaliação consiste em interrogar de diferentes modos os impactos e efeitos de um programa/política através da definição de critérios, indicadores e padrões. A conclusão ou extinção do programa/política constitui a última etapa dessa sequência, e seria a morte ou extinção da mesma. Para Secchi (2010), uma política pública, após um período de maturação, se institucionaliza e ganha vida própria, o que por certo vai dificultar sua extinção. $O$ autor exemplifica que não são raros os casos em que uma política pública continua viva mesmo após ter sumido o problema que a originou.

Nessa incursão resumida pelas etapas/fases da abordagem sequencial e de outras abordagens, alguns fluxos pelos quais a pesquisa transitou foram salientados.

Cabe acrescentar que, no Rio Grande do Sul, o transporte escolar público é, de longa data, uma temática complexa, principalmente quando o foco é seu financiamento e sua oferta. Assim, no estudo realizado, foi reconstruída analiticamente a política estadual de transporte escolar e, por conseguinte, a constituição do Peate, programa que transfere recursos financeiros diretamente aos municípios que realizem, nas suas respectivas áreas de circunscrição, o transporte escolar de alunos da Educação Básica da rede pública estadual, 
residentes no meio rural. Para tanto, foram pesquisadas, como já mencionado, a emergência do problema, a colocação da agenda, a definição de alternativas, a elaboração e a implementação da política pública do transporte/Peate, a fim de situar, em perspectiva histórica e relacional, atores, interesses, ideias e instituições que circunscreveram sua gênese e suas práticas.

\section{PALAVRAS FINAIS.... DE CHEGADA}

Por ora, compreendemos que a tarefa dessa produção, que se propôs percorrer possibilidades de ferramentas para analisar a política do transporte escolar gaúcho, chega a seu itinerário final.

Dentre as políticas públicas educacionais que visam a garantir acesso, permanência e sucesso/qualidade, destacamos o transporte escolar rural como um dos meios para que muitos brasileiros tenham garantido seu direito à educação. No Rio Grande do Sul, a opção política do governo estadual e, principalmente, dos municípios, pela não municipalização aprofundada das matrículas do Ensino Fundamental colocou a política de transporte escolar em evidência. Em que sentido ela ficou em evidência? No sentido de que ela acaba por ser uma temática que tem feito aflorar conflitos antigos de correlação de forças entre governo estadual e municípios; tem despertado disputas por recursos; tem denunciado a restrita capacidade financeira dos municípios na oferta educacional; tem traduzido a cooperação limitada no regime de colaboração entre os entes; tem apontado a função supletiva insuficiente da União e tem potencializado a construção de novas políticas, como a do Peate/RS.

\section{REFERÊNCIAS}

CAPELLA, Ana Cláudia Niedhardt. Perspectivas teóricas sobre o processo de formulação de políticas públicas. In: Encontro Anual da Anpocs, 29, 2005, Caxambu: Anais...; São Paulo: Anpocs, 2005.

FARENZENA Nalú. Assistência da União na Educação Básica: referenciais de políticas de gestão em foco. Políticas Educativas, Porto Alegre, v. 8, n. 1, p. 51 67, jul./dez. 2014.

. Responsabilidades públicas para com as políticas públicas de educação:

algumas reflexões. Políticas Educativas, Porto Alegre, v. 5, n. 1, p. 96-112, 2011. 
FREY, Klaus. Políticas públicas: um debate conceitual e reflexões referentes à prática da análise de políticas públicas no Brasil. Planejamento e Políticas Públicas, Brasília, n. 21, p. 211-259, jun. 2000.

KINGDON, John. Como chega a hora de uma ideia? In: SARAVIA, Enrique; FERRAREZI, Elisabete. Políticas públicas: coletânea, v. 1. Brasília: ENAP, 2006. p. 219-224.

LEVINSKI, Eliara Zavieruka. Política pública do ensino municipal: gênese, construção e manifestações. Passo Fundo: digitado, 2011.

MERRIEN, François-Xavier. Du néolibéralisme à la nouvelle gouvernance libérale. In: GIRAUD, Olivier; WARIN, Philipe. Politiques publiques et démocratie. Paris: La Découverte/PACTE, 2008. p. 321-333

MULLER, Pierre. Las políticas públicas. Colombia: Universidad Externado de Colombia, 2010.

. L'analyse cognitive des politiques publiques: vers une sociologie politique de l'action publique. Revue Française de Science Politique, Paris, v. 50, n. 2, p. 189-208, 2000. Tradução feita por Marta Petrik (2012).

; SUREL, Ives. Análise das políticas públicas. Pelotas: EDUCAT, 2002.

OLIVEIRA, Francisco. Crítica à razão dualista/O ornitorrinco. São Paulo: Boitempo, 2003.

PARADA, Eugenio Lahera. Políticas y políticas públicas. In: SARAIVA, Enrique; FERRAREZI, Elisabete (org.). Políticas públicas: coletânea. Brasília: ENAP, 2006.

PERGHER, Calinca Jordânia. Política de transporte escolar rural no Rio Grande do Sul: configuração de competências e de relações (inter)governamentais na oferta e no financiamento. Porto Alegre: UFRGS, 2014. 237 f. Tese (Doutorado em Educação) - Programa de Pós Graduação em Educação, Faculdade de Educação, Universidade Federal do Rio Grande do Sul, Porto Alegre, 2014. 
SECCHI, Leonardo. Políticas públicas: conceitos, esquemas de análise, casos práticos. São Paulo: Cengage Learning, 2010.

SOUZA, Celina. Políticas públicas: conceitos, tipologias e subáreas. Salvador: digitado, 2005.

CALINCA JORDÂNIA PERGHER é pedagoga, mestre e doutora em Educação pela UFRGS. Professora do Instituto Federal Farroupilha - Campus Alegrete e do Programa de pós-graduação PROFEPT. E-mail calincap@gmail.com

NALÚ FARENZENA é mestre e doutora em Educação, professora da Faculdade de Educação e do Programa de pós-graduação da UFRGS. E-mail: nalu.farenzena@, gmail.com

Recebido em outubro de 2015 Aprovado em novembro de 2015 